\title{
Dr. Lindberg: An Enduring Source of Inspiration
}

\author{
George R. THOMA Ph.D. ${ }^{1}$ \\ Chief, Communications Engineering Branch \\ Lister Hill National Center for Biomedical Communications \\ U.S. National Library of Medicine (retired)
}

Keywords: Donald A.B. Lindberg M.D., U.S. National Library of Medicine, Lister Hill National Center for Biomedical Communications

\section{Introduction}

The most vivid impression I retain about Donald A.B. Lindberg M.D. is the sheer breadth of his vision for the National Library of Medicine (NLM) and indeed for the medical community. Dr. Lindberg's insights and contributions to medical informatics and related fields are well established, but equally remarkable was his philosophy of 'Let a hundred flowers bloom, let a hundred schools of thought contend' (credited initially to Mao Zedong) when it came to NLM.

Dr. Lindberg envisioned opportunities far beyond the confines of a traditional medical library and of medicine itself. He perceived NLM and its many and diverse arms as vehicles to ultimately enrich people's lives in America and around the world.

Much of Dr. Lindberg's vision translated to projects across NLM, including several in the Communications Engineering Branch, part of the Lister Hill National Center for Biomedical Communications' Engineering Branch, an NLM research division. I began as an engineer in the branch in 1974 and had the privilege to lead it from 1984-2018. I outline some of these initiatives in this article, emphasizing Dr. Lindberg's critical role.

\section{Curiosity Befitting a Renaissance Man}

To come to my memories of Dr. Lindberg, one of his most enduring (and endearing) characteristics was his curiosity. He was interested, without a doubt, in everything!

For example, when Dr. Lindberg discovered I wrote a couple of papers on image compression, he wanted to know more. Compression became necessary as my team scanned documents and $\mathrm{x}$-rays for several ongoing projects. This resulted in very large files that seriously challenged both networks (for transmission) and storage devices (for archiving). Dr. Lindberg expressed interest in the design of our compression algorithms, which I tried to explain through diagrams and equations. Years later, when speaking at my retirement in 2018, to my surprise, he recalled this work - though honestly, I had forgotten most of the details.

\footnotetext{
${ }^{1}$ Corresponding author: georgethoma44@gmail.com
} 
Dr. Lindberg's insatiable curiosity led him to topics far afield. For instance, he learned a colleague, George Fonger, was a fossil hunter with a background in paleontology. While Fonger's job at NLM's Specialized Information Systems division had little to do with the latter discipline, Dr. Lindberg enjoyed studying the marine fossils dug up from the banks of the lower Potomac River. The fossils included shark teeth and oyster shells from the Paleocene era. Fonger affectionately recounted their conversations as I joined him in collecting these artifacts on summer trips at a site near the Chesapeake Bay.

I suggest curiosity also led Dr. Lindberg to explore the Internet and to understand how important the network would turn out to be, far earlier than other physicians and scientists - including the leadership of the National Institutes of Health (NIH) and its institutes and centers. Regarding Internet assistance, Dr. Lindberg sought the best and the brightest in this area as in many others, but also invited innovative pioneers to share their knowledge with the staff. I remember talks in NLM's auditorium by Bob Kahn and Vincent Cerf - both widely credited for the origins of the Internet. From these luminaries and others, Dr. Lindberg foresaw the potential of the Internet as a game-changer in the search for and delivery of medical information. In a relatively short time he introduced Medline, NLM's flagship database, as a free service available on the Internet, a boon for clinicians and researchers worldwide.

\section{Pushing the Envelope - Early Recognition of the Power of Artificial Intelligence}

In the winter of 1995-96, Dr. Lindberg paid me an unexpected visit that had a farreaching effect on my career as well my colleagues who worked in Lister Hill's engineering branch. Specifically, the meeting encouraged us to enter the new, burgeoning field of machine learning, a subfield of the discipline referred to as Artificial Intelligence.

Dr. Lindberg explained NLM was experiencing a crisis. Politicians in downtown Washington DC were unable to stave off a U.S. government shutdown, which adversely interrupted one of NLM's primary health informational/educational services and required an innovative intervention. Specifically, NLM's contract for data entry was suspended by the shutdown, which meant staff was not entering bibliographic data into Medline. The latter resulted in a hiatus updating and maintaining the database of citations to the medical journal literature. Hence, Medline, the world's most critical and possibly life-saving medical information resource, was neither up-to-date nor optimally serving the world's medical and research communities.

Something needed to be done.

Dr. Lindberg immediately asked if our ongoing document imaging and optical character recognition (OCR) work could be refocused to extract bibliographic data from scanned articles automatically. I explained OCR would be a first step to convert pixels to text. Still, algorithms would be necessary to identify and extract author names, article titles, abstracts, author affiliations, and the like - all vital elements of Medline citation records previously manually entered.

Not only did Dr. Lindberg give me an immediate go-ahead, he directed the Library's indexing section to cooperate in this effort. Thus, the MARS project - a hastily contrived acronym standing for Medical Article Records System - was born with urgency as well as a compelling professional purpose. 
Dr. Lindberg was well aware of the pioneering nature of our efforts to develop machine-learning algorithms. Understanding the difficulties ahead, he said, "You folks do great engineering, but I hope you can do good computer science." I knew Dr. Lindberg meant that developing innovative algorithms and software was different from building systems based mainly on hardware, which was the branch's focus at the time.

Yet, we persevered and developed the first machine-learning algorithms that successfully automated the extraction of bibliographic data from journal articles for the next 20 years. Moreover, this early work set the stage for 25 years of contributions to machine learning (and later, deep learning) that was applied to other areas, such as the automatic identification of diseases (TB, malaria, cervical cancer) in medical images. In a very real sense, Dr. Lindberg's set priorities helped shape our own. He created the conditions that enabled Sameer Antani, Rodney Long, Stefan Jaeger, and many others in my branch to build advanced diagnostic systems and to publish hundreds of peerreviewed publications over the years - an effort that endures.

Although Dr. Lindberg supported the MARS project, he was prudent, which was another of his managerial attributes. To discover alternative automation approaches, Dr. Lindberg reached out to his friend Raj Reddy, the director of the Robotics Institute at Carnegie Mellon University. In 1996, Reddy identified a colleague, Robert Thibadeau, to whom we sent a few thousand images of the articles we used in our research. It turned out Dr. Thibadeau's proposed strategies were not materially different from our approach, and NLM abandoned work with his group. Yet, the incident struck me as emblematic of Dr. Lindberg's leadership. Although Dr. Lindberg was loyal to NLM, he was never parochial. He always prepared to look outside NLM for expertise and advice that would advance the Library.

\section{A Respect for NLM's Historic Treasures}

Dr. Lindberg's deep understanding of NLM's unique strengths included an appreciation of its historical collections, specifically the 'treasures' kept within our History of Medicine Division (HMD). Dr. Lindberg mused about the possibility of revealing these treasures to the public without letting people handle centuries-old medical books - for the obvious reasons that each is fragile and unique.

In the early 2000s, Mike Chung and Glenn Pearson, my branch colleagues, tackled image animation as a way to bring these treasures to life. Chung was a world-class computer graphics expert, and Dr. Pearson, a talented software developer. They formed a symbiotic relationship crucial to develop Turning The Pages (TTP). TTP is a computer program that facilitates the 'touching and turning' of a book's (scanned) pages, which gives a reader an almost realistic look and feel of the original.

To initiate TTP's development, we talked to HMD's Michael North, who selected some rare $16^{\text {th }}$-century books from the Library's historical collection. These included Vesalius's anatomy masterpiece, Gesner's studies on animals, Paré's book on surgery, and many others. North proposed he serve as a curator and provide notes as well as explanatory material to improve a reader's understanding of the accompanying text.

It should be noted that although the software for NLM's TTP was our own, the inspiration for it was a system with the same name created by the British Library. Dr. Lindberg and Kent Smith, NLM's then-deputy director, had encouraged me and Joe Fitzgerald (a talented graphic artist at the Lister Hill Center) to visit the British Library to see their system and perhaps use their software. Although the British Library staff 
were unfailingly congenial and wonderful hosts, I formed the impression that we would need to develop TTP on our own, which we did.

To reach a broad audience, NLM's TTP was created in different forms: software for a touch-sensitive monitor, a Web program, and software for iPads and iPhones. The monitor went into an elaborate hardwood cabinet in the Visitors Center on the Lister Hill building's first floor and proved to be popular with school children and adults visiting NLM. The Web program was readily accessible by patrons anywhere on the Internet, and hundreds downloaded our software to view the books on their iPads and iPhones.

\section{Ever the Francophile}

In about 2010, TTP underwent an exciting transformation that we anticipated would delight Dr. Lindberg. Guy Cobolet, the director of an important medical library in Paris (BIUM), was spending a sabbatical at NLM hosted by Michael North. Intrigued by North's description of TTP, Guy paid me a visit during which I suggested a French version of TTP.

I knew Dr. Lindberg as a Francophile would be interested, if not thrilled. Cobolet agreed to translate North's curatorial notes as well as the names of the controls on the displayed images. In turn, we created Tournez Les Pages, which was invoked by a click on a French tricolor on the TTP Web page (a click on an American flag brought the reader back to the English version.) With a slight dramatic flair, I showed the system to Dr. Lindberg on Bastille Day, the $14^{\text {th }}$ of July, and as expected, he was more than pleased. Thanks to Cobolet, we converted several books into the French version of TTP. However, we did not complete the entire collection since he returned to Paris for his day job. As Cobolet would have said: "C'est la vie!"

I knew, as others did that Dr. Lindberg had a love for French culture and language. Indeed, once at a meeting in his office, I mistakenly used Marseille (the city) for La Marseillaise, the French national anthem. Ever the teacher, he quickly corrected me, as my dad would have done - had my dad known French (which he did not). I felt that in educating me, Dr. Lindberg was acting instinctively in a parental role, an attitude that forever endeared me to him.

\section{NLM's Role in Global Disasters}

Always taking a macroscopic view of NLM's role in the world, Dr. Lindberg established disaster information and mitigation as new activities, primarily centered at NLM's Specialized Information Systems division. While large-scale disasters may not seem a natural fit for a library, Dr. Lindberg recognized that health information and tools were necessary to overcome the devastation that resulted from earthquakes, tsunamis, floods, and similar events. And health information and tools were indeed the province of NLM and its many and varied talented personnel.

In January of 2010, Haiti suffered a significant earthquake with hundreds of thousands of casualties. Pondering what my branch could do, I talked to Mike Gill and other colleagues. Although I did not know anything about disasters, I was confident parents would be looking for missing kids, friends for each other, and wives for their husbands for the immediate aftermath of a disaster. 
Consequently, we developed People Locator, a Web site that served as an electronic bulletin board where photos of missing people (and their names and ages) could be posted by friends and family, so others could report whether they were safe or not. Tens of thousands of photos of missing Haitians were posted and confirmed whether or not they were alive and well. The system was subsequently deployed in about 50 disasters worldwide until 2018, when we decided that social media could assume this role. However, the development of People Locator was a direct consequence of Dr. Lindberg's concern for people's lives and wellbeing and the atmosphere that he fostered to provide innovative solutions to health information barriers.

\section{NLM as Family}

From the moment he arrived at NLM, Dr. Lindberg took ownership of the institution in a deeply personal way. He treated staff as family. Every December, everyone was invited to the Christmas party hosted by Dr. and Mrs. Lindberg with handshakes and hugs all around (though hugs were received only from Mary!) This welcome year-end celebration often was graced by music. We had a troupe of gospel singers one year and staff member Earl Simmons singing solo in his deep baritone at other times. I also remember an accordion player and bell ringers from a nearby Kensington church. All were wonderful entertainments marking the holiday season and the end of another year in what has been called the 'Golden Age' of the National Library of Medicine.

Dr. Lindberg's vision of NLM as a family also is evidenced by two panoramic group photos of the entire staff - on both occasions in front of the main library building. The first picture was taken a year or two after his arrival. The second photo captured the staff gathered to form the number 175 in commemoration of the $175^{\text {th }}$ anniversary of the Army Surgeon General's Library - NLM's direct ancestor. Everyone on the staff, perhaps with a few exceptions, was included in both photos. In retirement, I cherish these photographs with the familiar faces I knew for so long.

\section{Last Thoughts}

It is hard to precisely gauge the impact of what parents or mentors do for us at the moment of their influence. But in retrospect, looking back on the years of support, guidance, advice, and even criticism, their contributions to one's growth and success seem more evident. So it has been with my remembrances of Dr. Lindberg. In filial affection, I write this memoir. 